\title{
Ocular flora in patients with intravitreal injections and topical antibiotic prophylaxis: antibiotic resistance patterns and susceptibility to antiseptic picloxydine
}

\section{Maria PhD, Doctor of science Budzinskaya}

Scientific Research Institute of eye diseases

Anait Khalatyan ( $\sim$ anaits92@gmail.com )

Scientific Research Institute of Eye diseases https://orcid.org/0000-0001-6255-5544

Marina Strakhovskaya

Lomonosov Moscow State University, Department of Biology; Federal Research and Clinical Center of Specialized Medical Care and Medical Technologies, Federal Medical and Biological Agency of Russia Vladimir Zhukhovitsky

Gamaleya National Research Centre for Epidemiology and Microbiology

\section{Research article}

Keywords: Intravitreal injections, Conjunctival isolates, Antibiotic resistance, Picloxydine dihydrochloride, Vitabact

Posted Date: April 2nd, 2019

DOI: https://doi.org/10.21203/rs.2.1757/v1

License: (c) (i) This work is licensed under a Creative Commons Attribution 4.0 International License.

Read Full License

Version of Record: A version of this preprint was published at International Journal of Ophthalmology on January 18th, 2020. See the published version at https://doi.org/10.18240/ijo.2020.01.13. 


\section{Abstract}

Background Repeated courses of topical ophthalmic antibiotics result in the increased resistance rates and changes in the composition of conjunctival flora with the significant increase of Staphylococcus epidermidis, the main causative agent of ocular infections. Antiseptic povidone-iodine is considered as a "gold standard" for prevention of infectious complications in eye surgery. Effectiveness of pre- and postinjection prophylaxis with topical antiseptics is under question. Methods Conjunctival swabs were taken in 4 groups of patients, 20 patients in each group $(n=80)$ : with 20 or more IVI and repeated courses of antibiotic eye drops; without IVI and ophthalmic operations in history (control group); with antibiotic eye drops Tobrex or antiseptic eye drops Vitabact (picloxydine) applied 3 days before the first IVI and 5 days after it. In the last two groups swabs were taken at baseline and after the treatment. Bactericidal effectiveness of picloxydine was studied in vitro against antibiotic sensitive and resistant conjunctival isolates. Minimal inhibition concentration was determined with microdilution test. Results Two out of three potent ophthalmic patients showed conjunctiva bacterial contamination. Along with few Staphylococcus aureus and Gram-negative isolates susceptible to most antibiotics, the majority (71 77\%) were coagulase-negative staphylococci (CoNS), 40-50\% of which multidrug resistant (MDR). Eye disinfection in the operating room and peri-injection courses of Tobrex or Vitabact resulted in total elimination of isolates found at baseline. However, in 10 and $20 \%$ patients, respectively, recolonization of the conjunctiva with differing strains occurred. In patients with repeated IVI and Tobrex/Maxitrol treatment, the conjunctival flora showed high resistance rates: $90 \%$ of CoNS were MDR. In the in vitro study, picloxydine showed bactericidal effect against staphylococci isolates regardless of their antibiotic sensitivity with MIC $\geq 13,56 \mu \mathrm{g} / \mathrm{ml}$. Incubation of bacteria for $15 \mathrm{~min}$ in Vitabact eye drops, commercially available form of picloxydine, $434 \mu \mathrm{g} / \mathrm{ml}$, showed total loss of colony forming units of all tested isolates including Pseudomonas aeruginosa. Conclusions The confirmed bactericidal efficacy of picloxydine against conjunctival bacterial isolates and the presence of its commercial form, $0,05 \%$ eye drops, convenient for use by patients before and after injection, makes this eye antiseptic promising for prophylaxis of IVI-associated infectious complications.

\section{Background}

Intravitreal injections (IVIs) are one of the effective, widespread and minimally invasive methods of treatment of various retinal diseases. The effectiveness of such therapy is observed in treatment of exudative age-related macular degeneration, edema, associated with diabetic retinopathy or retinal vein occlusions. Due to a noticeable increase in the incidence of diabetes mellitus and cardiovascular diseases it is expected that the number of IVIs will steadily continue to rise. Generally, IVI is a safe procedure. However, like any surgical intervention, it carries the risk of potential complications. Infectious complications, associated with IVIs, occur, when a pathogen from the eye surface in the site of the injection penetrates the vitreous capacity. The most dangerous complication is the infectious endophthalmitis with visual impairment threat even in a case of proper and early treatment [1,2]. 
The importance of antimicrobial treatment accompanying the IVI procedure is obvious. However, to date, there is no single approach to the management of patients regarding the use of antibacterial eye drops before and and/or after IVI as a prevention method of inflammatory infectious complications. In 2004 when the practice of IVI was just introduced, ophthalmic antibiotics were widely used for this purpose [3]. But unlike other ocular surgeries, conducted once or twice in a patient's life, where topical antibiotics may be an appropriate prophylactic measure, IVIs are often repeated to the same eye [4]. In such patients, short-term repeated courses of topical antibiotics accompanying IVI may not only reduce the risk of infectious complications but actually enhance it by increasing antibiotic resistance of conjunctival flora. In recent years, this has been confirmed in several studies.

Coagulase-negative staphylococci (CoNS), the most common bacteria on the eye surface [5], demonstrated increased rates of resistance to fluoroquinolones if isolated from eyes repeatedly exposed to one of the following ophthalmic antibiotics ofloxacin/gatifloxacin/moxifloxacin hydrochloride [6]. As shown in the study, CoNS isolates from azithromycin-exposed eyes were characterized by increased macrolide resistance. The predominant CoNS strain Staphylococcus epidermidis developed coresistance to trimethoprim/sulfamethoxazole, gentamicin and clindamycin in fluoroquinolone-exposed eyes and to trimethoprim/sulfamethoxazole and doxycycline in azithromycin-exposed eyes [7]. Milder et al. [8] and Dorrepaal et al. [9] also found the increased antibiotic resistance of conjunctival flora due to repeated use of fluoroquinolone drops. The selection of resistant bacteria requires not so much time. Thus, bacteria colonies with high resistance to gatifloxacin were isolated from the eye of the patient who received only 3 IVI with a prophylactic use of this topical antibiotic [9].

Along with the increased resistance, repeated courses of topical eye antibiotics cause changes in the composition of conjunctival flora with the significant increase in the percentage of $S$. epidermidis [10]. The authors note the clinical significance of this fact because $S$. epidermidis is the main causative agent of ocular infections.

Grzybowski et al. [5] consider IVI to be "a prime example where unnecessary and/or improper use of antibiotics may have serious consequences". An alternative may be the use of antiseptics with efficacy comparable to antibiotics such as povidone-iodine or biguanides. Barkana et al. [11] proved that there was no significant difference between povidone-iodine, chlorhexidine (cationic biguanide) and ofloxacin in terms of reduction of conjunctival flora, $91.2 \%, 87.6 \%$ and $85.6 \%$, respectively. Merani et al. [12] showed that aqueous chlorhexidine used as an antiseptic drug before IVI was well tolerated and effective in terms of low endophthalmitis rate. In conjunctival samples after the treatment with chlorhexidine $0,05 \%$, there was a significant reduction in the total bacterial load (82\%) and even greater results were observed for CoNS $(90 \%)$. In this study by Gili et al. [13], no povidone-iodine was administered to the patient, eye irrigation was performed only using $0,05 \%$ chlorhexidine solution.

When comparing povidone-iodine and chlorhexidine, first is still considered as a "gold standard" for prophylaxis of infectious complications in eye surgery [12]. Along with efficacy, application of brown colored povidone-iodine, in contrast of colorless chlorhexidine, is easier for surgeon due to the visible 
areas of irrigation. However, povidone-iodine has its deficiencies. There is a cohort of patients with povidone sensitivity, not true immunoglobulin E-mediated allergy [14]. Sensitivity can be expressed in conjunctival hyperemia, irritation (mild to severe) and pain. In these cases, surgeon should consider using another antiseptic drug, for example chlorhexidine. Thus, Oakley and Vote [15] switched povidone-iodine to $0,1 \%$ chlorhexidine solution in patients reporting high levels of pain. As the result, the average pain score decreased from 8 of 10 points to 3 of 10 .

Another antiseptic from the group of biguanides is picloxydine dihydrochloride commercially available as Vitabact, $0,05 \%$. These approved eye drops could be useful in pre- and post-injection prophylaxis of eye infections. However, we found no data on the use of Vitabact in the management of patients with IVI.

In the study, we confirmed the increased resistance of conjunctival flora in patients with multiple IVI and antibiotic eye drops courses in anamnesis. We compared effectiveness of antiseptic Vitabact and antibiotic Tobrex eye drops in the eye surface decontamination. In the in vitro experiments, the bactericidal effect of Vitabact eye drops was proved against both antibiotic sensitive and resistant conjunctival bacterial isolates.

\section{Methods}

This was a prospective case-control study comparing 4 groups of patients, 20 patients in each group $(\mathrm{n}=80): 1)$ patients who received 20 or more IVI and the concomitant courses of antibiotic eye drops Tobrex based on aminoglycoside tobramycin, in some courses it was replaced by Maxitrol containing aminoglycoside neomycin, polymyxin B and dexamethasone (group 1);2) patients of the control group, comparable in age, without IVI and ophthalmic operations in history (group 2); 3) patients with the first IVI who have applied antibiotic eye drops Tobrex 3 days before the IVI and within 5 days after it (group 3); 4) patients with the first IVI who have applied antibacterial eye drops Vitabact (picloxydine) 3 days before the IVI and within 5 days after it.

Exclusion criteria for all groups were the following: age younger 50 years old, use of systemic antibiotics within 3 months, use of ocular hypotensive drops for the glaucoma management; besides that, use of antibiotic drops and ocular surgery were exclusion criteria for the second, third and fourth groups.

All patients were recruited from the Research Institute of Eye Diseases in Moscow, Russia. The Local biomedical ethics committee of the Research Institute of Eye Diseases approved the protocol (protocol № 49/4). Informed written consent was obtained from each patient before participation in the study.

In the standard IVI procedure, the eyelid skin and the area around the eye were treated with a $10 \%$ solution of iodopyrone. Next, eyelid speculum was applied. Local anesthetic drops of Alcaine were instilled in the conjunctival sac. The conjunctival cavity was irrigated for 30 seconds with 2,0 $\mathrm{ml}$ of $5 \%$ povidone-iodine and then with saline solution to wash away povidone residue. 
Conjunctival swabs were performed by using sterile disposable tampons using a standard procedure (from lateral to medial angle of the eye) in the lower conjunctival fornix to the Amies transport system, which maintains the viability of microorganisms from the time of the material collection to the beginning of the study. Care was taken to minimize the contact with lashes, eyelids and skin. In the groups of patients 3 and 4 conjunctival swabs were taken both before (at baseline) and the next day after the end of post-injection treatment with Tobrex or Vitabact.

In positive swabs, the isolated microorganisms were identified and tested for antibiotic susceptibility by BD Phoenix 100 automated identification and susceptibility testing system.

The in vitro bactericidal effects of picloxydine in the form of commercially available eye drops Vitabact were analyzed with the broth microdilution test. The Trypticase Soy Broth (TSA; Becton Dickinson, France)) containing a series of double-diluted Vitabact in the range 1:2 - 1:32 (corresponded to picloxydine $217,00-13,56 \mu \mathrm{g} / \mathrm{ml}$ ) or without Vitabact in control samples was used for bacterial growth. Three colonies of each isolate grown for $24 \mathrm{~h} \mathrm{370C}$ on Columbia agar (Becton Dickinson, France) with $5 \%$ sheep blood plates were suspended in phosphate buffer saline (PBS, pH 7,4) with density adjusted to 0.5 McFarland. These stock suspensions were used to inoculate $(20 \mu \mathrm{l})$ samples of nutrient broth $(200 \mu \mathrm{l})$ in sterile 96-well plates. The absorbance of bacterial cultures was recorded with Perkin Elmer Wallac 1420 Multilabel Counter (Sweden) at $490 \mathrm{~nm}$ at the initial moment, after inoculation, as well as after 24 and 96 $h$ growth at $370 \mathrm{C}$. To confirm the bactericidal effect of picloxydine probes from the wells were inoculated in Columbia agar plates and cultivated at 370C 24 hours. The bactericidal effect of Vitabact eye drops was studied with incubation of bacteria, 108 colony forming units (CFU)/ml, directly in Vitabact (434 $\mu \mathrm{g} / \mathrm{ml}$ picloxydine) for $15 \mathrm{~min}$ at $250 \mathrm{C}$ or diluted in phosphate buffer saline (PBS, pH 7,4) 1:16 Vitabact, $27,12 \mu \mathrm{g} / \mathrm{ml}$ picloxydine, for $60 \mathrm{~min}$ at $250 \mathrm{C}$. The loss of CFU was controlled by subsequent cultivation on agar plates at $370 \mathrm{C}$ within $24 \mathrm{~h}$. The independent experiments were performed in triplicate.

Statistical analysis was conducted with SPSS via contrasting the respective $95 \%$ and $99 \%$ confidence intervals (based on the estimates of group means and standard deviations).

\section{Results}

\section{Ocular flora and antibiotic resistance patterns}

A total of 120 conjunctival swabs from 80 eyes were collected during the study. Of these 120 swabs, 59 isolates were cultured. Staphylococcus epidermidis composed the body $(66,10 \%, 39 / 59)$ of isolates, followed by $S$. aureus $(11,86 \%, 7 / 59)$, S. hominis $(6,78 \%, 4 / 59)$, S. haemolyticus $(5,08 \%, 3 / 59)$. Also, 1 isolate $(1,69 \%, 1 / 59)$ of each was obtained: $S$. caprae, $S$. lugdunensis, and Gram-negative microorganisms - Enterococcus cloacae, Escherichia coli, Pseudomonas aureginosa and P. Iuteola.

In the control group (20 eyes), microflora growth was detected in 14 swabs (70\%). In terms of species composition, all the 14 isolated cultures (Table 1) were Gram-positive staphylococci: S. epidermidis was isolated in 11 patients $(78,57 \%, 11 / 20)$, the rest three were S. caprae, S. hominis and S. aureus, each 
$7,14 \%(1 / 14)$. That is, $92,86 \%(13 / 14)$ of the isolates were CoNS. In this group, the single $S$. aureus isolate was sensitive to all drugs among 21 tested except chloramphenicol. Among 13 CoNS, 1 was antibiotic sensitive and 3 strains each were resistant to drugs of 1, 2, 3 or 4 antibiotics classes (Table 2). That is, 6 isolates can be attributed to multidrug resistant (MDR). Methicillin-resistant staphylococci (MRS) made up $30,77 \%$ (4/13) of CoNS isolates (Fig. 1). Almost the third of the isolates $(30,77 \%, 4 / 13)$ were resistant to gentamicin and tobramycin. Rather high percentage $(23,08 \%, 3 / 13)$ of CoNS were resistant to erythromycin or ciprofloxacin.

In the group of 20 patients with IVI and antibiotic eye drops Tobrex prophylaxis, the swabs were obtained before (20 eyes) and after (20 eyes) this treatment. Like in the control group, at baseline before the treatment microflora growth was observed in 14 swabs $(70 \%, 14 / 20)$. In one case, Gram negative Enterobacter cloacae was isolated (Table 1). The remaining 13 cases represented different types of staphylococci, including 3 S. aureus $(23,08 \%, 3 / 13)$ and 10 CoNS $(76,92 \%, 10 / 13)$. One of the $S$. aureus isolates was antibiotic sensitive, the second resistant to penicillin $G$ and the third to tobramycin and tetracycline. As for 10 CoNS, 2 isolates were sensitive to all tested drugs, 3 isolates showed resistance to drugs from 2 antibiotic classes and 5 were MDR (Table 2). Among CoNS isolates, 30\% (3/10) belonged to MRS, 20\% (2/10) were gentamicin and tobramycin and 20\% (2/10) - ciprofloxacin resistant (Fig. 1). This corresponded to the control group. However, in the groups of ophthalmic patients before IVI and Tobrex treatment, the percentage of erythromycin resistant CoNS reached $70 \%(7 / 10)$ that was much higher as compared with the control group. Doxycycline resistant isolates were found in group of patients before IVI and Tobrex treatment but not in the control group (Fig. 1).

Table 1. Bacterial species, their number ( $n$ ) and percentage, isolated from conjunctival swabs in different groups of patients 


\begin{tabular}{|c|c|c|c|c|c|c|c|c|}
\hline Groups & $\begin{array}{l}\text { Control } \\
\text { group }\end{array}$ & & $\begin{array}{l}\text { Group } 3 \\
\text { before } \\
\text { the first } \\
\text { IVI and } \\
\text { antibiotic } \\
\text { eye drops } \\
\text { treatment }\end{array}$ & & $\begin{array}{l}\text { Group } 3 \\
\text { after } \\
\text { the first } \\
\text { IVI and } \\
\text { antibiotic } \\
\text { eye drops } \\
\text { treatment }\end{array}$ & & $\begin{array}{l}\text { Group } \\
\text { after } \\
\text { multiple } \\
\text { IVI and } \\
\text { antibiotic } \\
\text { eye drops } \\
\text { treatments }\end{array}$ & \\
\hline Microorganism & $\mathrm{n}$ & $\%$ & $\mathrm{n}$ & $\%$ & $\mathrm{n}$ & $\%$ & $\mathrm{~N}$ & $\%$ \\
\hline Gram-positive & 14 & 100 & 13 & 92,86 & 2 & 100,0 & 11 & 91,66 \\
\hline S. epidermidis & 11 & 78,57 & 7 & 50,0 & & & 8 & 66,66 \\
\hline S. caprae & 1 & 7,14 & - & & & & & \\
\hline $\begin{array}{l}\text { S. } \\
\text { haemolyticus }\end{array}$ & & & 1 & 7,14 & & & 2 & 16,66 \\
\hline S. hominis & 1 & 7,14 & 2 & 14,29 & 1 & 50,0 & & \\
\hline S. Iugdunensis & & & & & 1 & 50,0 & & \\
\hline S. aureus & 1 & 7,14 & 3 & 21,43 & & & 1 & 8,33 \\
\hline Gram-negative & 0 & 0 & 1 & 7,14 & 0 & 0 & 1 & 8,33 \\
\hline $\begin{array}{l}\text { Enterobacter } \\
\text { cloacae }\end{array}$ & & & 1 & 7,14 & & & & \\
\hline $\begin{array}{l}\text { Pseudomonas } \\
\text { aeruginosa }\end{array}$ & & & & & & & 1 & 8,33 \\
\hline
\end{tabular}

In the same group of 20 patients after IVI and treatment with Tobrex (20 eyes), only two conjunctival swabs were positive. In one patient, no growth was observed in swabs taken at the first visit, and after the treatment with Tobrex and IVI, sensitive $S$. hominis was isolated (Table 1). In the swabs of the second patient $S$. haemolyticus resistant to erythromycin, chloramphenicol and fosfomycin (includes glucose-6phosphate) was isolated in the first visit, and $S$. Iugdunensis resistant to fosfomycin was obtained at the second visit.

In the group of 20 patients (20 eyes) who received 20 or more IVI and peri-injection prophylaxis with antibiotic eye drops, 11 swabs were positive $(55 \%, 11 / 20)$, one of them gave the growth of 2 isolates $(S$. epidermidis and $S$. haemolyticus). Eleven cultures were staphylococci (Table 1), among them 10 were CoNS, $80 \%(8 / 10)$ S. epidermidis and $20 \%(2 / 10)$ S. haemoyticus. The rest one was S. aureus. In addition, Gram negative $P$. aeruginosa was detected in 1 case.

Table 2. Antibiotic resistant isolates from conjunctival swabs in different groups of patients 


\begin{tabular}{|c|c|c|c|c|c|c|c|}
\hline Groups & $\begin{array}{l}\text { Control } \\
\text { group }\end{array}$ & & $\begin{array}{l}\text { Group } \\
\text { before the } \\
\text { first IVI } \\
\text { and } \\
\text { antibiotic } \\
\text { eye drops } \\
\text { treatment }\end{array}$ & & $\begin{array}{l}\text { Group } \\
\text { after the } \\
\text { first IVI } \\
\text { and } \\
\text { antibiotic } \\
\text { eye drops } \\
\text { treatment }\end{array}$ & & $\begin{array}{l}\text { Group } \\
\text { after } \\
\text { multiple } \\
\text { IVI and } \\
\text { antibiotic } \\
\text { eye drops } \\
\text { treatments }\end{array}$ \\
\hline $\begin{array}{l}\text { Number of } \\
\text { antibiotics - A and } \\
\text { antibiotic classes - } \\
\text { AC to which } \\
\text { resistance has } \\
\text { been detected, in } \\
\text { brackets ( } \mathrm{n}) \\
\text { number of isolates }\end{array}$ & $A(n)$ & $\begin{array}{l}A C \\
\text { (n) }\end{array}$ & $A(n)$ & $\begin{array}{l}A C \\
\text { (n) }\end{array}$ & $A(n)$ & $\begin{array}{l}A C \\
\text { (n) }\end{array}$ & $A(n)$ \\
\hline
\end{tabular}

\section{Gram-positive}

S. epidermidis

$0(1) \quad 0(1) \quad 0(2)$

$0(2)$

4(1)

3(2)

1(3)

1(3) 2(2)

2(3)

5(2)

2(2) 2(3) 3(2)

3(1)

6(2)

$4(1) \quad 3(2) \quad 7(1) \quad 4(1)$

7(2)

11(1)

5(3) $\quad 4(2)$

12(1)

6(1)

\begin{tabular}{|c|c|c|c|c|c|c|c|c|}
\hline S. caprae & $3(1)$ & $3(1)$ & - & - & - & - & - & - \\
\hline \multirow[t]{2}{*}{ S. haemolyticus } & - & - & $3(1)$ & $3(1)$ & - & - & $3(1)$ & $2(1)$ \\
\hline & & & & & & & $7(1)$ & $4(1)$ \\
\hline \multirow[t]{2}{*}{ S. hominis } & $4(1)$ & $4(1)$ & $5(1)$ & $4(1)$ & $0(1)$ & $0(1)$ & - & - \\
\hline & & & $9(1)$ & $6(1)$ & & & & \\
\hline S. Iugdunensis & - & - & - & - & $1(1)$ & $1(1)$ & - & - \\
\hline \multirow[t]{3}{*}{ S. aureus } & $1(1)$ & $1(1)$ & $0(1)$ & $0(1)$ & - & - & $3(1)$ & $2(1)$ \\
\hline & & & $1(1)$ & $1(1)$ & & & & \\
\hline & & & $2(1)$ & $2(1)$ & & & & \\
\hline
\end{tabular}

\section{Gram-negative}

Enterobacter cloacae 
As for antibiotic sensitivity in the group with multiple IVI and antibiotic eye drops treatment, we found no CoNS sensitive or resistant to $1 \mathrm{drug}$. Only one isolate was resistant to antibiotic of two classes (Table 2). MRS were $50 \%(5 / 10)$ of CoNS isolates. Moreover, the conjunctival flora in such patients was characterized by an increase in the number of strains resistant to a wide range of antibiotics. Nine of 10 CoNS were MDR (90\%). Among these, we found S. epidermidis isolate resistant to 11 antibiotic classes. In this group of patients who have received repeated courses of aminoglycoside-containing eye drops Tobrex/Maxitrol, $90 \%$ (9/10) CoNS and the single isolate of $S$. aureus were gentamicin and tobramycin resistant (Fig. 1). This threatening situation encouraged us to try antiseptic picloxydine-containing eye drops Vitabact in peri-injection antimicrobial prophylaxis.

In the group of 20 patients who were prescribed antiseptic eye drops Vitabact 3 days before the first IVI (20 eyes) and within 5 days after it (20 eyes), the swabs of $6(30 \%, 6 / 20)$ patients were negative at baseline and after the treatment. From 13 positive baseline swabs $(65 \%, 13 / 20)$, the majority $(92,31 \%$, 12/13) gave staphylococci growth. Ten CoNS isolates were represented by S. epidermidis (Table. 3). Out of 10,4 S. epidermidis isolates were MDR $(40 \%, 4 / 10)$. Both $S$. aureus isolates were resistant to penicillin $\mathrm{G}$ and one of them to ampicillin. In one case the rare Pseudomonas luteola were isolated. The latter was sensitive to all antibiotics tested. After IVI and prophylaxis with Vitabact the swabs of 10 of these patients were negative. In 3 patients $(15 \%, 3 / 20)$, S. epidermidis growth was observed both before and after post-injection treatment with Vitabact. However, the cultures isolated before and after the treatment differed in their resistance to certain antibiotics, which indicates the elimination of the primary isolated strain as a result of the Vitabact treatment and secondary infection with another strain of S. epidermidis. In 1 patient $(5 \%, 1 / 20)$, swab was negative before the treatment, but after the treatment antibioticsensitive E. coli was isolated, which can also be explained by secondary infection due to eye hygiene breaches. In general, $80 \%$ of swabs taken next day after the end of the treatment with Vitabact were negative.

Table 3. Bacterial species, their number ( $n$ ) and percentage, isolated from conjunctival swabs in group of patients with the first IVI and antiseptic eye drops Vitabact treatment 3 days before and 5 days after it

\begin{tabular}{lllll} 
Group with Vitabact & Before the treatment & & After the treatment & \\
\cline { 1 - 4 } Microorganism & $\mathrm{N}$ & $\%$ & $\mathrm{~N}$ & $\%$ \\
\hline Gram-positive & 12 & 92,31 & $\mathbf{3}$ & $\mathbf{7 5 , 0}$ \\
\hline S. epidermidis & 10 & 76,92 & 3 & 75,0 \\
\hline S. aureus & 2 & 15,38 & - & - \\
\hline Gram-negative & 1 & 7,69 & $\mathbf{1}$ & 25,0 \\
\hline Pseudomonas luteola & 1 & 7,69 & - & - \\
\hline Escherichia coli & - & - & 1 & 25,0
\end{tabular}




\section{Bactericidal efficacy of picloxydine against conjunctival isolates}

Picloxydine (Vitabact) bactericidal efficacy against conjunctival isolates was confirmed in the in vitro study. In these experiments we analyzed the growth in picloxydine-containing nutrient broth of the following 44 staphylococci isolates: 5 S. aureus (1 antibiotic sensitive, 4 resistant to 1-2 antibiotic classes), 33 S. epidermidis (2 antibiotic sensitive, 15 resistant to 1-2 antibiotic classes and 16 MDR), $2 S$. haemolyticus (1 resistant to 2 antibiotic classes and 1 MDR), $3 S$. hominis ( 1 sensitive and 2 MDR), $1 S$. caprae (MDR). Three Gram-negative isolates were also included in the study: P. aeruginosa, $P$. Iuteola and E. coli.

After 24 hours, we did not detect growth of any staphylococci in series of liquid growth media containing double-diluted Vitabact (from 1:2 to 1:32) that corresponded to decrease in picloxydine concentration from 217,00 to $13,56 \mu \mathrm{g} / \mathrm{ml}$. Control suspensions without Vitabact showed bacteria growth, as observed by absorbance increase. In Table 4 we summarized the growth parameters of staphylococci isolates in nutrient broth without addition or in the presence of Vitabact in its lowest concentration (1:32 dilution) tested in our study. In order to identify possible differences in the Vitabact effect on MDR strains, coagulase-negative staphylococci that made up the most of isolates were grouped by their sensitivity. $S$. aureus formed one group, as among the few $S$. aureus MDR strains were not isolated. We found no differences (at any reasonable statistical significance level) in picloxydine inhibitory effect on growth of isolates, MDR or resistant to no more than two drugs, as well as CoNS and $S$. aureus.

After $96 \mathrm{~h}$ growth, the absorbance changes were insignificant as compared with $24 \mathrm{~h}$ for all groups apart from $S$. aureus ( $24 \mathrm{~h}$ vs $96 \mathrm{~h}$ ). For the latter, there is an indication of statistical difference at $5 \%$ level, although the groups are not statistically different at $1 \%$ level. Only one isolate, $S$. epidermidis resistant to clindamycin, chloramphenicol and erythromycin, showed the growth of absorbance to the value about 0,25 . Its contribution in the average MDR group absorbance after $96 \mathrm{~h}$ growth is seen from increased standard deviation (Table 4). The results again did not give a difference depending on antibiotic sensitivity and staphylococci species (Vitabact effect was statistically strong in all isolates at $1 \%$ level).

Probes of each staphylococci culture grown in nutrient broth for 24 or $96 \mathrm{~h}$ with or without Vitabact dilutions were cultivated further on agar plates within $24 \mathrm{~h}$. Those taken from picloxydine-containing liquid media samples showed no growth except one mentioned isolate with the lowest picloxydine concentration tested $(13,56 \mu \mathrm{g} / \mathrm{ml})$. These data confirmed bactericidal properties of Vitabact. Thus, the picloxydine minimal inhibitory concentration (MIC) for staphylococci conjunctival isolates $\geq 13,56 \mu \mathrm{g} / \mathrm{ml}$.

Among the Gram-negative bacteria, the most resistant was $P$. aeruginosa isolate. It grew in liquid medium even with $217,00 \mu \mathrm{g} / \mathrm{ml}$ picloxydine content (1:2 deluted Vitabact). E. coli and $P$. luteola were much more sensitive, the minimal picloxydine concentrations that inhibited the growth of these isolates for $24 \mathrm{~h}$ were 54,25 and $13,56 \mu \mathrm{g} / \mathrm{ml}$, respectively. Bactericidal effect during $96 \mathrm{~h}$ growth in nutrient broth was detected with picloxydine concentrations $\geq 54,25 \mu \mathrm{g} / \mathrm{ml}$ for $E$. coli and $\geq 27,12 \mu \mathrm{g} / \mathrm{ml}$ for $P$. luteola. 
Table 4. Absorbance of staphylococci cultures in nutrient broth growing without addition or with Vitabact (1:32 dilution) that corresponds to $13,56 \mu \mathrm{g} / \mathrm{ml}$ of picloxydine, mean and standard deviations (in brackets)

\begin{tabular}{|c|c|c|c|c|c|c|c|}
\hline \multirow[t]{3}{*}{ Isolates } & \multirow{3}{*}{$\begin{array}{l}\text { Antibiotic } \\
\text { resistance } \\
\text { ( } \mathrm{n}=\text { number of } \\
\text { isolates) }\end{array}$} & \multirow{2}{*}{\multicolumn{2}{|c|}{$\begin{array}{l}\text { Growth } \\
\text { time } \\
\text { without } \\
\text { Vitabact, h }\end{array}$}} & & \multirow{2}{*}{$\begin{array}{l}\text { Growth } \\
\text { time with } \\
\text { Vitabact } \\
\text { (1:32 } \\
\text { dilution), h }\end{array}$} & \multirow[b]{3}{*}{24} & \multirow[b]{3}{*}{96} \\
\hline & & & & & & & \\
\hline & & 0 & 24 & 96 & 0 & & \\
\hline \multirow[t]{2}{*}{ S.aureus } & \multirow{2}{*}{$\begin{array}{l}\text { Sensitive or } \\
\text { resistant to } 1-2 \\
\text { drugs }(n=5)\end{array}$} & 0,106 & 0,857 & 0,745 & 0,106 & 0,116 & 0,099 \\
\hline & & $(0,003)$ & $(0,121)$ & $(0,160)$ & $(0,002)$ & $(0,012)$ & $(0,008)$ \\
\hline \multirow[t]{4}{*}{ CoNS } & \multirow{2}{*}{$\begin{array}{l}\text { Sensitive or } \\
\text { resistant to } 1-2 \\
\text { drugs }(n=19)\end{array}$} & 0,106 & 0,723 & 0,603 & 0,108 & 0,111 & 0,104 \\
\hline & & $(0,002)$ & $(0,142)$ & $(0,174)$ & $(0,004)$ & $(0,011)$ & $(0,010)$ \\
\hline & \multirow[t]{2}{*}{$\operatorname{MDR}(n=20)$} & 0,107 & 0,712 & 0,667 & 0,105 & 0,119 & 0,114 \\
\hline & & $(0,002)$ & $(0,189)$ & $(0,223)$ & $(0,006)$ & $(0,013)$ & $(0,034)$ \\
\hline
\end{tabular}

Incubation of $P$. aeruginosa or $E$. coli $(108 \mathrm{CFU} / \mathrm{ml})$ directly in Vitabact $(434 \mu \mathrm{g} / \mathrm{ml}$ picloxydine $)$ for $15 \mathrm{~min}$ caused complete loss of CFU as observed by subsequent cultivation on agar plates at $370 \mathrm{C}$ within $24 \mathrm{~h}$. Moreover, incubation of these isolates in diluted $1: 16$ Vitabact, $27,12 \mu \mathrm{g} / \mathrm{ml}$ picloxydine in PBS $(\mathrm{pH} 7,4)$, for $60 \mathrm{~min}$ led to the same. Therefore, lower concentrations of picloxydine were required to achieve a bactericidal effect toward Gram-negative bacteria in the absence of the components of nutrient broth. Staphylococci (4 S. epidermidis, 2 antibiotic sensitive and 2 MDR, 2 S. hominis, sensitive and MDR, $S$. caprae, $S$. haemolyticus and 2 S. aureus) exposed $15 \mathrm{~min}$ to Vitabact or $60 \mathrm{~min}$ to 1:16 diluted Vitabact $(27,12 \mu \mathrm{g} / \mathrm{ml}$ picloxydine in PBS) lost CFU, that is complete bactericidal effect was achieved.

\section{Discussion}

In our study, at least two out of three potent ophthalmic patients showed conjunctiva bacterial contamination: in the groups $3(n=20)$ and $4(n=20)$ the baseline swabs of 14 and 13 patients were positive. Consistent with other studies, reviewed in [5], the majority were CoNS (71 - 77\%) followed by S. aureus $(15-21 \%)$ and single Gram-negatives. Among CoNS the most frequently isolated was $S$. epidermidis $(70-100 \%)$. S. epidermidis is believed to prevent the colonization of conjunctiva by more serious pathogens [16]. CoNS (93\%, $87 \%$ of these $S$. epidermidis) and S. aureus (7\%) constituted the ocular flora in the control group $1(n=20)$.

Antibiotic resistance rate of ocular flora and especially CoNS in potent ophthalmic patients (groups 3 and 4, preoperatively) requires increased attention when prescribing pre- and post-injection prophylactic antimicrobials. Along with S. aureus and Gram-negative isolates susceptible to most antibiotics, $40-50 \%$ CoNS in our study were MDR. In view of the continuing practice of antibiotic eye drops prophylactic peri- 
injection treatment in Russian Federation, we should mention that CoNS resistant to gentamycin/tobramycin were found in $20 \%$ and to moxifloxacin in $10 \%$ of potent ophthalmic patients.

In patients who have received 20 or more IVI and concomitant prophylactic courses of antibiotic therapy, a significant increase in the resistance of the conjunctival flora to a wide range of antibiotics was observed. Percentage of MDR strains reached $75 \%$ among all isolates and doubled among CoNS ( $90 \%$ ). These patients received courses of antibiotic eye drops Tobrex based on aminoglycoside tobramycin (in some courses replaced by Maxitrol containing aminoglycoside neomycin, polymyxin B and dexamethasone). As the result, we found 4,5 times increase of tobramycin resistant strains ( $90 \%)$ as compared with those isolated preoperatively in the groups 3 and $4(20 \%)$. Thus, we strongly suggest susceptibility testing in patients who are planning to undergo repeated IVI. The results of the test would help the surgeon to avoid prescribing unnecessary and even threatening antibacterial drug and to choose the most appropriate one.

Nowadays asepsis and antisepsis are beneficial rather than use of topical antibiotics as a prevention method of post-injection complications [4]. Aseptic and antiseptic techniques include performing injections in the operating rooms, application of povidone-iodine and peri-injection prophylactic treatment with antiseptic drops. Ultraclean air and good ventilation are required in operating rooms [2]. In order to reduce the risk of infection, the spread of pathogens from the oral cavity of patients and medical personnel should be minimized [17] by using sterile masks by surgeons and nurses and sterile adhesive eye drapes that isolate patients' nasopharyngeal area and periocular region [18]. It is important to prevent the contact of eyelashes and eyelid margins from the injection site and the needle, through which the medication is injected into the vitreous cavity. This can be achieved by using an eyelid speculum which remove the eyelashes, potential source of infection of the needle tip [17]. The preparation of the ocular surface should include irrigation with a solution of povidone-iodine for at least 30 seconds [19]. Precisely, irrigation of the conjunctiva is needed, not a drop application of the solution, that corresponds to Safar and Dellimore [20] findings. A single application of povidone-iodine demonstrates a bactericidal effect, equivalent to the 3-day course of local antibiotics [21]. Several studies have shown that resistance to povidone-iodine does not develop $[22,23]$ unlike the reported reduced levels of susceptibility to chlorhexidine [24], so we can safely continue using povidone-iodine solution in the operating rooms.

As to pre- and post-injection prophylaxis, in patients, who used the Vitabact antibacterial eye drops 3 days before the first IVI and within 5 days after it, $80 \%$ of swabs taken the day after the end of the treatment were negative. Thus, the effectiveness of a single pre- and post-injection course of Vitabact was close to that of Tobrex ( $90 \%$ negative swabs). In positive conjunctival swabs taken the day after the end of postinjection treatment with Tobrex or Vitabact, 2 and 4 isolates were found, respectively. However, these isolates differed in their resistance to certain antibiotics from those found at baseline in the same patients. This means that the isolates found at baseline were eliminated with the povidone-iodine irrigation before the injection and/or eye drops treatment. Most likely, after the end of the eye drops postinjection treatment a rapid, within one day, recolonization of the conjunctiva occurred. 
In the in vitro study with microdilution test, picloxydine had bactericidal effect against 39 CoNS, $5 \mathrm{~S}$. aureus, E. coli and P. luteola isolates regardless of their antibiotic sensitivity. The picloxydine MIC for staphylococci $\geq 13,56 \mu \mathrm{g} / \mathrm{ml}$. Another test with incubation of bacteria $15 \mathrm{~min}$ in Vitabact eye drops, commercially available form of picloxydine with concentration $434 \mu \mathrm{g} / \mathrm{ml}$, resulted in total loss of CFU of 10 conjunctival Gram-positive isolates, both antibiotic sensitive or MDR, and Gram-negative $E$. coli and $P$. aeruginosa.

\section{Conclusions}

The confirmed bactericidal efficacy of picloxydine against conjunctival bacterial isolates and the presence of its commercial form, $0,05 \%$ eye drops, convenient for use by patients before and after injection, makes this eye antiseptic promising for prophylaxis of IVI-associated infectious complications.

\section{Abbreviations}

IVI: intravitreal injections CoNS: coagulase-negative staphylococci

MDR: multidrug resistant MR: methicillin-resistant staphylococci

CFU: colony forming units PBS: phosphate buffer saline

\section{Declarations}

\section{Ethics approval and consent to participate}

All patients were recruited from the Research Institute of Eye Diseases in Moscow, Russia. The Local biomedical ethics committee of the Research Institute of Eye Diseases approved the protocol (protocol №49/4). Informed written consent was obtained from each patient before participation in the study.

\section{Consent for publication}

Not applicable.

\section{Availability of data and material}

The datasets used and/or analysed during the current study are available from the corresponding author (Khalatyan Anait S.) upon reasonable request.

\section{Competing interests}

The authors declare that they have no competing interests.

\section{Funding}

None. 


\section{Authors contributions}

BMV, SMG and ZVG carried out the study concept and design. BMV, KAS, SMG and ZVG collected and interpreted the data, researched relevant literature. KAS performed the statistical analysis. All authors wrote the manuscript and approved the final manuscript.

\section{Acknowledgements}

Not applicable.

\section{References}

1. Schwartz SG, Flynn HW, Grzybowski A. Controversies in Topical Antibiotics Use with Intravitreal Injections. Curr Pharm Des. 2015;21(32):4703-6.

2. Lau PE, Jenkins KS, Layton CJ. Current Evidence for the Prevention of Endophthalmitis in Anti-VEGF Intravitreal Injections. J Ophthalmol. 2018:8567912.

3. Aiello LP, Brucker AJ, Chang S, Cunningham ET Jr, D'Amico DJ, Flynn HW Jr, Grillone LR, Hutcherson S, Liebmann JM, O'Brien TP, Scott IU, Spaide RF, Ta C, Trese MT. Evolving guidelines for intravitreous injections. Retina. 2004;24(5 Suppl):S3-19.

4. Hunyor AP, Merani R, Darbar A, Korobelnik JF, Lanzetta P, Okada AA. Topical antibiotics and intravitreal injections. Acta Ophthalmol. 2018;96(5):435-41.

5. Grzybowski A, Brona P, Kim SJ. Microbial flora and resistance in ophthalmology: a review. Graefe's Arch Clin Exp Ophthalmol. 2017;255(5):851-62.

6. Kim SJ, Toma HS. Antimicrobial resistance and ophthalmic antibiotics: 1-year results of a longitudinal controlled study of patients undergoing intravitreal injections. Arch Ophthalmol. 2011;129(9):1180-8.

7. Dave SB, Toma HS, Kim SJ. Ophthalmic antibiotic use and multidrug-resistant Staphylococcus epidermidis: a controlled, longitudinal study. Ophthalmology. 2011;118(10):2035-40.

8. Milder E, Vander J, Shah C, Garg S. Changes in antibiotic resistance patterns of conjunctival flora due to repeated use of topical antibiotics after intravitreal injection. Ophthalmology. 2012;119(7):1420-4. 9. Dorrepaal SJ, Gale J, El-Defrawy S, Sharma S. Resistance of ocular flora to gatifloxacin in patients undergoing intravitreal injections. Can J Ophthalmol. 2014;49(1):66-71.

10. Dave SB, Toma HS, Kim SJ. Changes in ocular flora in eyes exposed to ophthalmic antibiotics. Ophthalmology 2013;120(5): 937-41.

11. Barkana Y, Almer Z, Segal O, Lazarovitch Z, Avni I, Zadok D. Reduction of conjunctival bacterial flora by povidone-iodine, ofloxacin and chlorhexidine in an outpatient setting. Acta Ophthalmol Scand. 2005;83(3):360-3. 
12. Merani R, McPherson ZE, Luckie AP, Gilhotra JS, Runciman J, Durkin S, Muecke J, Donaldson M, Aralar A, Rao A, Davies PE. Aqueous chlorhexidine for intravitreal injection antispepsis: a case series and review of the literature. Ophthalmology. 2016;123 (12):2588-94.

13. Gili NJ, Noren T, Törnquist E, Crafoord S, Bäckman A. Preoperative preparation of eye with chlorhexidine solution significantly reduces bacterial load prior to 23-gauge vitrectomy in Swedish health care. BMC Ophthalmology. 2018;18(1):167.

14. Lachapelle JM. A comparison of the irritant and allergenic properties of antiseptics. Eur J Dermatol. 2014;24(1):3-9.

15. Oakley $\mathrm{CL}$, Vote BJ. Aqueous chlorhexidine $(0.1 \%)$ is an effective alternative to povidone-iodine for intravitreal injection prophylaxis. Acta Ophthalmol. 2016;94(8):e808-e809.

16. Lina G, Boutite F, Tristan A, et al. Bacterial competition for human nasal cavity colonization: role of staphylococcal agr alleles. Appl Environ Microbiol. 2003;69(1):18-23.

17. Avery RL, Bakri SJ, Blumenkranz MS, Brucker AJ, Cunningham ET Jr, D'Amico DJ, Dugel PU, Flynn HW Jr, Freund KB, Haller JA, Jumper JM, Liebmann JM, McCannel CA, Mieler WF, Ta CN, Williams GA. Intravitreal injection technique and monitoring: updated guidelines of an expert panel. Retina. 2014;34(Suppl 12):S1-S18.

18. Huang K, Sultan MB, Zhou D, Tressler C S, Mo J. Practice patterns of ophthalmologists administering intravitreal injections in Europe: a longitudinal survey. Clin Ophthalmol. 2016;10:2485-88.

19. Bhavsar AR, Glassman AR, Stockdale CR, Jampol LM \& Diabetic Retinopathy Clinical Research Network (2016): Elimination of topical antibiotics for intravitreous injections and the importance of using povidoneiodine: update from the Diabetic Retinopathy Clinical Research Network. JAMA Ophthalmol. 2016;134(10):1181-3.

20. Safar A, Dellimore MC. The effect of povidone iodine flush versus drops on conjunctival colonization before intravitreal injections. Int Ophthalmol. 2007;27(5):307-12.

21. Isenberg SJ, Apt L, Yoshimori R, Khwarg S. Chemical preparation of the eye in ophthalmic surgery. IV. Comparison of povidone-iodine on the conjunctiva with a prophylactic antibiotic. Arch Ophthalmol. 1985;103(9):1340-2.

22. Lanker Klossner B, Widmer HR, Frey F. Nondevelopment of resistance by bacteria during hospital use of povidone-iodine. Dermatology. 1997;195(Suppl 2):10-3.

23. Hsu J, Gerstenblith AT, Garg SJ \& Vander JF. Conjunctival flora antibiotic resistance patterns after serial intravitreal injections without post-injection topical antibiotics. Am J Ophthalmol. 2014;157(3):514-8. 
24. Horner C, Mawer D, Wilcox M. Reduced susceptibility to chlorhexidine in staphylococci: is it increasing and does it matter? J Antimicrob Chemother. 2012;67(11):2547-59.

\section{Figures}

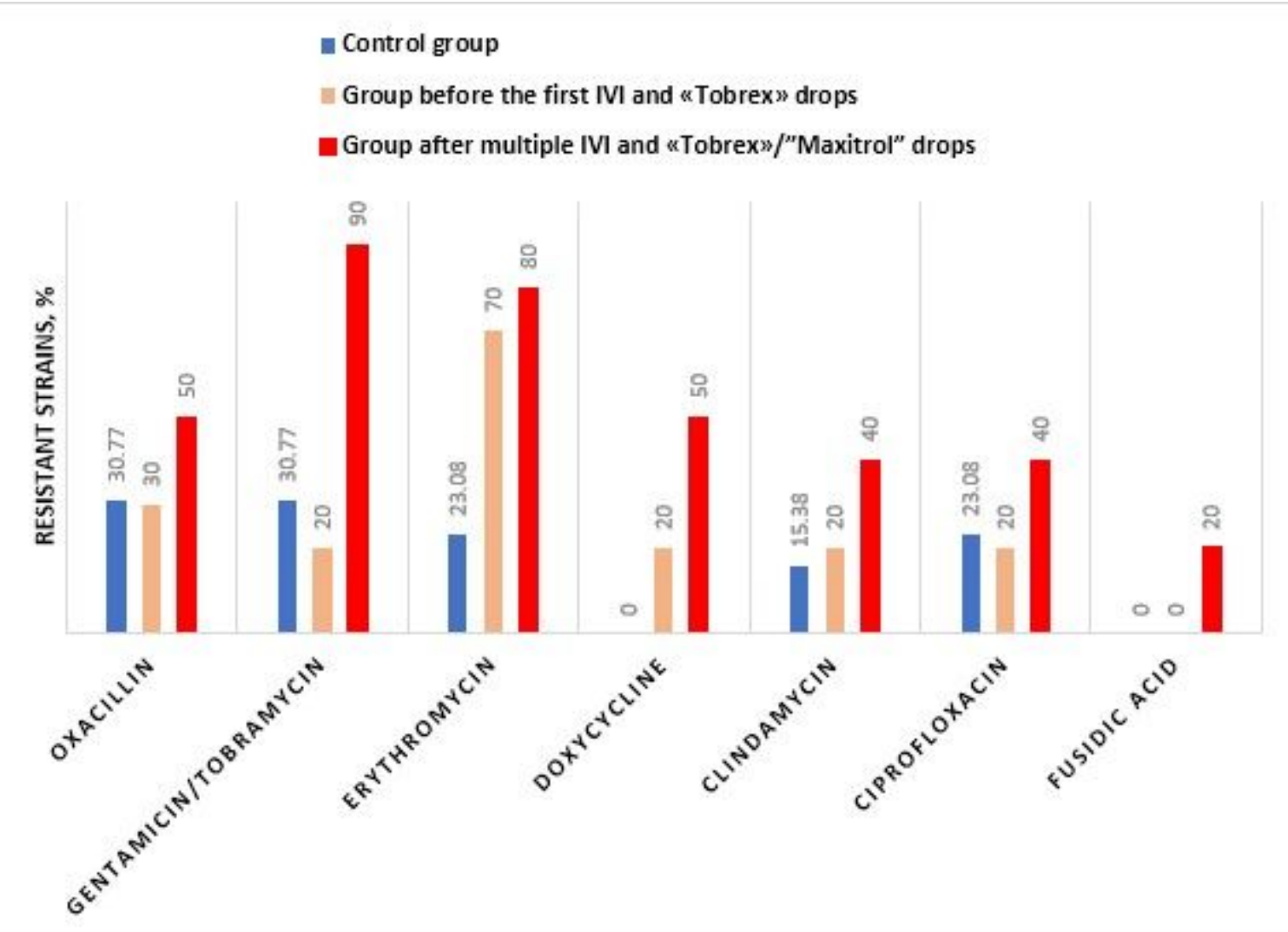

Figure 1

Percentage of antibiotic resistant coagulase-negative Staphylococcus spp. (CoNS) isolates in different groups of patients 